\title{
Dominant Frontotemporal Dementia Mutations in 140 Cases of Primary Progressive Aphasia and Speech Apraxia
}

\author{
Eoin P. Flanagan ${ }^{a}$ Matthew C. Baker ${ }^{\mathrm{e}}$ Ralph B. Perkerson ${ }^{\mathrm{e}}$ \\ Joseph R. Duffy ${ }^{b}$ Edythe A. Strand ${ }^{b}$ Jennifer L. Whitwell ${ }^{c}$ \\ Mary M. Machuldad Rosa Rademakers ${ }^{\mathrm{e}}$ Keith A. Josephs ${ }^{a}$ \\ Divisions of a Behavioral Neurology and b Speech Pathology, Department of Neurology, and \\ Departments of ${ }^{\mathrm{C}}$ Radiology and ${ }^{\mathrm{d}}$ Psychiatry and Psychology, Mayo Clinic, Rochester, Minn., \\ and ${ }^{~}$ Department of Neuroscience, Mayo Clinic, Jacksonville, Fla., USA
}

\section{Key Words}

Genetics · C9ORF72 - MAPT - Progranulin · Apraxia of speech · Semantic dementia ·

Logopenic progressive aphasia - Progressive nonfluent aphasia · PPA

\begin{abstract}
Background: Mutations in three genes [chromosome 9 open-reading-frame 72 (C9ORF72); microtubule-associated protein tau (MAPT) and progranulin (GRN)] account for the vast majority of familial, and a proportion of sporadic, frontotemporal dementia (FTD) cases. Progressive apraxia of speech (PAOS) is a type of FTD characterized by speech production deficits without a known cause. Methods: We therefore assessed for genetic mutations in C9ORF72, MAPT and GRN in 40 prospectively recruited PAOS patients. For comparison, we also assessed these mutations in 100 patients with primary progressive aphasia (PPA), including logopenic PPA ( $n=54)$, nonfluent/agrammatic PPA $(n=17)$, semantic PPA $(n=16)$, and unclassifiable PPA $(n=13)$. Results: The mean age at onset of PAOS patients was 66.7 years $( \pm 9.3) ; 50 \%$ were women. Ten patients (25\%) had $\geq 1$ first-degree relative with a neurodegenerative disease. No mutations were found in any PAOS patient. In comparison, $36 \%$ of the PPA patients had a family history and $5(5 \%)$ had a genetic mutation detected: MAPT $(\mathrm{n}=0), \operatorname{GRN}(\mathrm{n}=3)$ and C9ORF72 $(\mathrm{n}=2)$. Conclusions: Although limited by an overrepresentation of logopenic PPA, which frequently predicts Alzheimer's disease pathology, this study suggests that mutations in the three genes most commonly associated with FTD are not associated with PAOS and are not commonly associated with PPA.


Flanagan et al.: Dominant Frontotemporal Dementia Mutations in 140 Cases of Primary Progressive Aphasia and Speech Apraxia

\section{Introduction}

Apraxia of speech (AOS) is a motor speech disorder characterized by difficulties in the planning and programming of speech. Progressive AOS (PAOS) is a neurodegenerative disorder which presents with isolated AOS [1] or with AOS as the dominant feature [2]. PAOS is associated with involvement of the lateral premotor and supplementary motor cortex [1-3]. Over time, PAOS patients become mute, and some evolve into having a Parkinson-plus syndrome [4]. The pathology underlying PAOS is an abnormal tau deposition [3]. Due to these features, PAOS is considered a subtype of frontotemporal dementia (FTD). Currently there is no known cause of PAOS.

The discovery of three causative mutations accounting for approximately $80 \%$ of autosomal dominant familial FTD cases has revolutionized our understanding of FTD [5]. These three causative mutations are: mutations in the microtubule-associated protein tau (MAPT) gene on chromosome 17q21.1 [6]; mutations in the progranulin (GRN) gene on chromosome $17 q 21.32$ [7], and a hexanucleotide repeat expansion (GGGGCC) in the intronic (non-coding) region of chromosome 9 open-reading-frame 72 (C9ORF72) [8]. These mutations may be found in sporadic cases of FTD [5] and in cases of primary progressive aphasia (PPA), another neurodegenerative disease that overlaps with FTD. PPA differs from PAOS, as language disturbance, not motor speech dysfunction, is the cardinal feature [9]. Additionally, PPA is divided into three variants: (1) a progressive nonfluent/agrammatic variant (agPPA); (2) a semantic variant (svPPA), and (3) a logopenic variant (lvPPA) [10]. In comparison to PPA, genetic studies of patients with PAOS are more limited, although a case of PAOS with a MAPT gene mutation has been reported [11].

The aim of this study therefore was to determine whether any of the three causative mutations of FTD and PPA, MAPT, GRN and C9ORF72, would account for the clinical syndrome of PAOS. In addition, we set out to compare the frequency of mutations in PAOS to the frequency in PPA. We hypothesized that mutations in MAPT, but not GRN or C9ORF72, would be associated with PAOS. We also hypothesized that mutations in GRN and C9ORF72 would be more frequent in PPA than in PAOS.

\section{Subjects and Materials}

Participants and Speech and Language Assessment

All adult patients ( $\geq 18$ years old) presenting to the Mayo Clinic in Rochester, Minn., USA, with a progressive speech or language disorder were recruited prospectively from July 2010 to July 2014. All participants underwent a detailed speech and language assessment as previously described [2]. Detailed family histories were recorded at the time of evaluation by the evaluating neurologist (K.A.J.).

\section{Diagnostic Criteria}

PAOS was diagnosed based on published criteria by two speech and language pathologists who came to consensus for all cases. PAOS was diagnosed when the presentation was consistent with a progressive speech disorder in which AOS was found to be an isolated feature or the predominant feature of the presenting syndrome [2]. Similarly, patients were diagnosed as PPA by both speech and language pathologists and subclassified into one of its variants (agPPA, svPPA and lvPPA) based on published criteria [10]. Those meeting criteria for PPA but unable to be subclassified were defined as unclassifiable PPA [12].

Standard Protocol Approvals, Registrations and Patient Consents

The study was approved by the Mayo Clinic Institutional Review Board, and all patients in our study consented to the use of their medical record for research purposes. 


\begin{tabular}{l|l}
\hline DOI: $10.1159 / 000375299$ & $\begin{array}{l}\text { C } 2015 \text { S. Karger AG, Basel } \\
\text { www.karger.com/dem }\end{array}$ \\
\hline
\end{tabular}

Flanagan et al.: Dominant Frontotemporal Dementia Mutations in 140 Cases of Primary Progressive Aphasia and Speech Apraxia

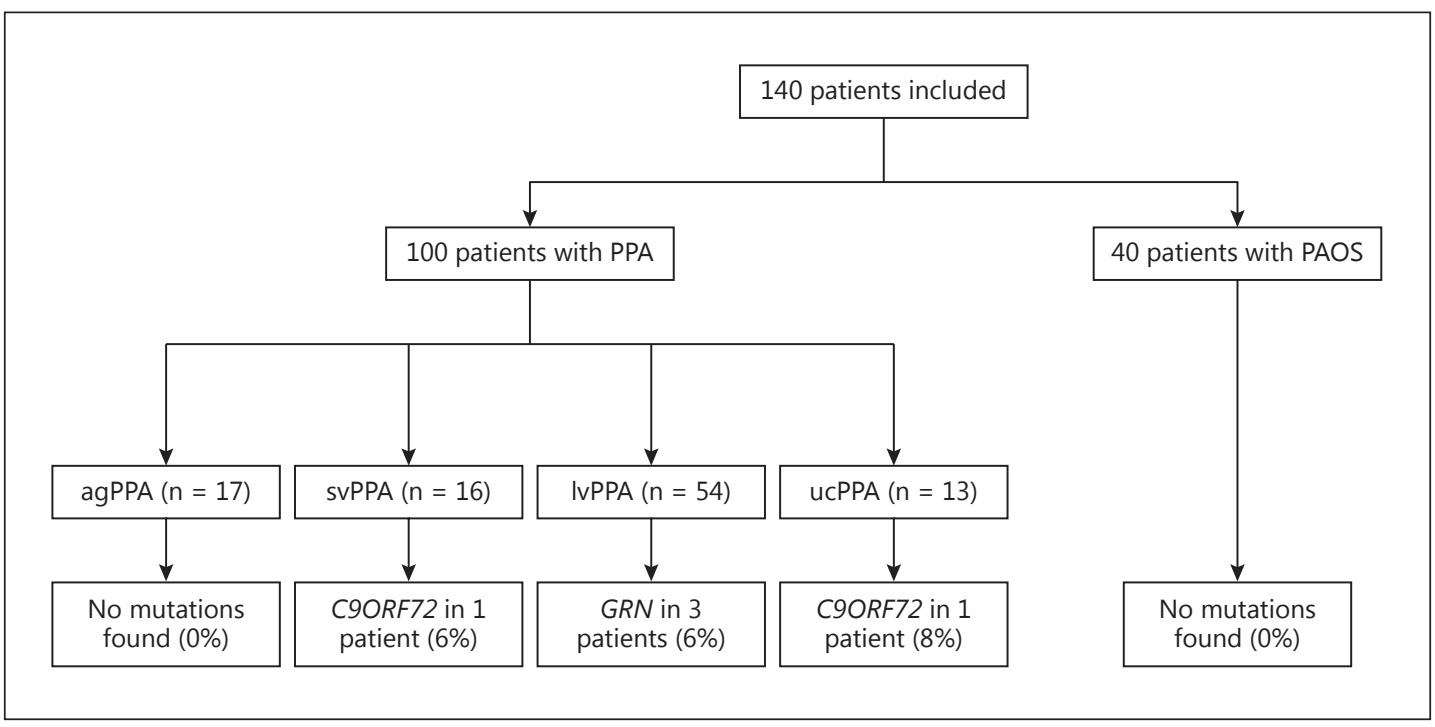

Fig. 1. Genetic mutations in PPA variants and PAOS. ucPPA = Unclassifiable PPA.

Genetic Methods

Amplification by polymerase chain reaction (PCR) of exons 0-12 and the $3^{\prime}$ untranslated region of the GRN gene as well as of the exons 1, 7 and 9-13 of the MAPT gene was performed using primers and protocols that have been previously described [6, 7]. Purification of the amplicons from the PCR was undertaken as previously described [13]. To assess for the presence of an expanded GGGGCC hexanucleotide repeat in C9ORF72, the repeat primed PCR was also used, as outlined in a previous publication [8].

\section{Results}

A total of 140 patients were included in our study with the following diagnoses: PAOS $(\mathrm{n}=40)$ and PPA $(\mathrm{n}=100)$, as shown in figure 1 .

\section{PAOS Patients}

The demographic features of the 40 PAOS patients are shown in table 1 . Ten patients $(25 \%)$ had a family history of a neurodegenerative disease $(86 \%$ of which were 1 st-degree relatives; $20 \%$ of those with a family history had multiple 1st-degree relatives), including: Alzheimer's disease $(n=4)$; Parkinson's disease $(n=4)$; dementia not otherwise specified (NOS; $n=1$ ), and amyotrophic lateral sclerosis (ALS; $n=1$ ). The age at onset of relatives with neurodegenerative disorders was $<60$ years in $8.3 \%, 60-70$ years in $58.3 \%$ and $>70$ years in $33.3 \%$ of the cases.

Results of Genetic Testing

In the 40 PAOS patients, no mutations were detected in MAPT, C9ORF72 or GRN.

\section{PPA Patients}

The demographic features of the 100 PPA patients are shown in table 1. Of the 99 PPA patients with details available (1 patient was adopted), 36 patients (36\%) had a family history of a neurodegenerative disease $(77 \%$ of which were 1 st-degree relatives; $19 \%$ of those with 
Dementia

Cognitive Disorders

Table 1. Demographics of the 140 PAOS and PPA patients

\begin{tabular}{l|l}
\hline Dement Geriatr Cogn Disord 2015;39:281-286 \\
\hline DOI: 10.1159/000375299 & $\begin{array}{l}\text { @ 2015 S. Karger AG, Basel } \\
\text { www.karger.com/dem }\end{array}$ \\
\hline
\end{tabular}

Flanagan et al.: Dominant Frontotemporal Dementia Mutations in 140 Cases of Primary Progressive Aphasia and Speech Apraxia

\begin{tabular}{|c|c|c|}
\hline Demographic features & $\begin{array}{l}\text { PAOS } \\
(n=40)\end{array}$ & $\begin{array}{l}\text { PPA } \\
(n=100)\end{array}$ \\
\hline Age at onset, years & $66.7 \pm 9.3$ & $63.6 \pm 8.0$ \\
\hline Females, n (\%) & $20(50)$ & $51(51)$ \\
\hline Right-handed patients, n (\%) & $34(85)$ & $91(91)$ \\
\hline Education, years & $15.2 \pm 2.8$ & $15.6 \pm 2.8$ \\
\hline $\begin{array}{l}\text { Illness duration at the time of our evaluation, } \\
\text { years }\end{array}$ & $3.7 \pm 1.8$ & $3.8 \pm 5.6$ \\
\hline $\begin{array}{l}\text { Mini-Mental State Examination score at } \\
\text { evaluation }\end{array}$ & $28.2 \pm 2.0$ & $23.9 \pm 7.5$ \\
\hline Clinical Dementia Rating Scale sum of boxes & $2.4 \pm 1.4$ & $4.7 \pm 3.8$ \\
\hline
\end{tabular}

Data are shown as mean \pm standard deviation, unless indicated otherwise.

a family history had multiple 1st-degree relatives), including: dementia NOS ( $\mathrm{n}=10)$; Alzheimer's disease $(n=16)$; Parkinson's disease $(n=5)$; PPA $(n=3)$, and ALS $(n=2)$. The age at onset of relatives with neurodegenerative disorders was $<60$ years in $2 \%, 60-70$ years in $58 \%$ and $>70$ years in $40 \%$ of the cases.

Results of Genetic Testing

Five $(5 \%)$ of the PPA patients had mutations in either GRN $(\mathrm{n}=3)$ or C9ORF72 (n = 2; fig. 1). All 3 patients with GRN mutations had a sibling with PPA. Of the 2 patients with C9ORF72 repeat expansions, one had a brother with neurodegenerative dementia NOS with onset in his $60 \mathrm{~s}$, and the other had no family history. Both had presented with difficulty understanding telephone conversations. One patient showed right greater than left anteriomedial temporal lobe abnormalities.

\section{Discussion}

The results of this study demonstrate that mutations in the three genes (MAPT, GRN and C9ORF72) most commonly associated with FTD are not associated with PAOS. It also appears that these three mutations are also not commonly associated with PPA.

There have been no prior large genetic studies of PAOS, although 1 patient with PAOS and a P332S MAPT mutation has been described [11]. We had hypothesized that mutations in the $M A P T$ gene would be associated with PAOS, as the underlying pathology of PAOS is tau. However, we did not find any MAPT gene mutations in the 40 PAOS patients. Furthermore, we did not find a single tau mutation in any of the 140 patients in this study, including the 100 PPA patients. Since MAPT mutations have been previously described in patients with familial PPA $[14,15]$, it would not be unreasonable to conclude that MAPT mutations are rarely associated with the PAOS and PPA subtypes of FTD.

We also did not find any mutations in GRN or C9ORF72 in PAOS. However, we did find that in the group of PPA patients that fall under the general heading of FTD (agPPA and SVPPA) only $3 \%(1 / 33)$ had a mutation in one of these genes. GRN mutations have been previously described in all PPA variants [14-18], and C9ORF72 repeat expansions have been described in a few patients with svPPA and agPPA $[5,15]$. Our data suggest that a family history of PPA may be a clue to a $G R N$ mutation, while auditory verbal agnosia may be a clue to a C9ORF72 expansion. The low frequency among our PPA patients, however, contrasts with reports of 
Flanagan et al.: Dominant Frontotemporal Dementia Mutations in 140 Cases of Primary Progressive Aphasia and Speech Apraxia

these mutations accounting for approximately $25 \%$ of overall FTD cases [5]. One possible explanation is that we did not seek out PPA patients with family members already known to harbor mutations in these genes, or PPA patients with known family histories, as is the case with many centers that do genetic studies in FTD. Such practice is likely to inflate the frequency of mutations. Another possible explanation is that the majority of FTD patients with a mutation in one of these three genes have the behavioral variant of FTD (bvFTD), not PPA. These reasons may also explain the absence of a family history of bvFTD in our cohort, although it is also possible that family members were either not seen by a specialist or had been seen many years ago and had mistakenly been given diagnoses of Alzheimer's disease or dementia NOS rather than bvFTD. It should be noted, however, that while there are reports of cases and families with mutations occurring with PPA, a combined systematic analysis of these genes, in such large numbers as in this study, has never been reported.

While a family history of a neurodegenerative disorder in a 1st-degree relative was not uncommon, just $6 \%$ of the overall cohort had multiple 1 st-degree relatives with a neurodegenerative disease. The onset of symptoms in relatives was typically after 60 years of age, the clinical diagnosis, when known, was often Alzheimer's disease, and just 3 patients (3\%) had a family history of a neurodegenerative disease affecting language. Other studies have shown low frequencies of familial PPA including $17 \%$ in svPPA (1.9\% with an autosomal dominant pattern) and $27.6 \%$ in agPPA (6.9\% with an autosomal dominant inheritance) [19]. This compares to other variants of FTD such as bvFTD or ALS, in which $59.2 \%$ are familial and $37 \%$ have an autosomal dominant inheritance [19].

The low frequency of these autosomal dominant genetic mutations in PAOS and PPA has implications for clinical trials and suggests that it will be difficult to recruit genetically determined asymptomatic PAOS and PPA patients for prevention trials given the low numbers $(\leq 5 \%)$. One limitation of our study is that we did not assess less common mutations associated with FTD such as valosin-containing protein and charged multivesicular body position 2B [14].

This study suggests that the genetics of PAOS and PPA is unique and that other potential genes need to be assessed for potential associations, although the overrepresentation of patients with lvPPA, which - compared to agPPA and svPPA - is most often associated with an Alzheimer's disease pathology, may have contributed to the low number of FTD mutations in this cohort. Future studies of PAOS and PPA genetics should be analyzed separately from other FTD variants to help elucidate what genetic or other factors could be contributing to these phenotypes.

\section{Acknowledgements}

This study was supported by R01 DC 010367, R01 NS080882, P50 AG016574, and P50 NS072187. The funding bodies had no role in the design, collection, analysis or interpretation of the data, in the writing of the manuscript or in the decision to submit the manuscript for publication.

\section{Disclosure Statement}

J.R.D. and E.A.S. are funded by the NIH (NIDCD). J.L.W. and K.A.J. are funded by the NIH (NIA and NIDCD) and the Alzheimer's Association. M.M.M. is funded by the NIH (NIA and NIDCD). R.R. is funded by the NIH (NIA and NINDS), the ALS Therapy Alliance and the Consortium for Frontotemporal Dementia. There are no other conflicts of interest to disclose. 
Flanagan et al.: Dominant Frontotemporal Dementia Mutations in 140 Cases of Primary Progressive Aphasia and Speech Apraxia

\section{References}

1 Josephs KA, Duffy JR, Strand EA, Machulda MM, Senjem ML, Master AV, Lowe VJ, Jack CR Jr, Whitwell JL: Characterizing a neurodegenerative syndrome: primary progressive apraxia of speech. Brain 2012;135:15221536.

2 Josephs KA, Duffy JR, Strand EA, Machulda MM, Senjem ML, Lowe VJ, Jack CR Jr, Whitwell JL: Syndromes dominated by apraxia of speech show distinct characteristics from agrammatic PPA. Neurology 2013;81:337-345.

3 Josephs KA, Duffy JR, Strand EA, Whitwell JL, Layton KF, Parisi JE, Hauser MF, Witte RJ, Boeve BF, Knopman DS, Dickson DW, Jack CR Jr, Petersen RC: Clinicopathological and imaging correlates of progressive aphasia and apraxia of speech. Brain 2006;129:1385-1398.

4 Josephs KA, Duffy JR, Strand EA, Machulda MM, Senjem ML, Gunter JL, Schwarz CG, Reid RI, Spychalla AJ, Lowe VJ, Jack CR Jr, Whitwell JL: The evolution of primary progressive apraxia of speech. Brain 2014;137:27832795.

5 Loy CT, Schofield PR, Turner AM, Kwok JB: Genetics of dementia. Lancet 2014;383:828-840.

6 Hutton M, Lendon CL, Rizzu P, et al: Association of missense and 5'-splice-site mutations in tau with the inherited dementia FTDP-17. Nature 1998;393:702-705.

7 Baker M, Mackenzie IR, Pickering-Brown SM, et al: Mutations in progranulin cause tau-negative frontotemporal dementia linked to chromosome 17. Nature 2006;442:916-919.

8 DeJesus-Hernandez M, Mackenzie IR, Boeve BF, et al: Expanded GGGGCC hexanucleotide repeat in noncoding region of C90RF72 causes chromosome 9p-linked FTD and ALS. Neuron 2011;72:245-256.

9 Mesulam MM: Primary progressive aphasia - a language-based dementia. N Engl J Med 2003;349:1535-1542.

10 Gorno-Tempini ML, Hillis AE, Weintraub S, Kertesz A, Mendez M, Cappa SF, Ogar JM, Rohrer JD, Black S, Boeve BF, Manes F, Dronkers NF, Vandenberghe R, Rascovsky K, Patterson K, Miller BL, Knopman DS, Hodges JR, Mesulam MM, Grossman M: Classification of primary progressive aphasia and its variants. Neurology 2011; 76:1006-1014.

11 Deramecourt V, Lebert F, Maurage CA, Fernandez-Gomez FJ, Dujardin S, Colin M, Sergeant N, Buée-Scherrer V, Clot F, Ber IL, Brice A, Pasquier F, Buée L: Clinical, neuropathological, and biochemical characterization of the novel tau mutation P332S. J Alzheimers Dis 2012;31:741-749.

12 Wicklund MR, Duffy JR, Strand EA, Machulda MM, Whitwell JL, Josephs KA: Quantitative application of the primary progressive aphasia consensus criteria. Neurology 2014;82:1119-1126.

13 Whitwell JL, Weigand SD, Boeve BF, Senjem ML, Gunter JL, DeJesus-Hernandez M, Rutherford NJ, Baker M, Knopman DS, Wszolek ZK, Parisi JE, Dickson DW, Petersen RC, Rademakers R, Jack CR Jr, Josephs KA: Neuroimaging signatures of frontotemporal dementia genetics: C9ORF72, tau, progranulin and sporadics. Brain 2012;135:794-806.

14 Grossman M: Primary progressive aphasia: clinicopathological correlations. Nat Rev Neurol 2010;6:88-97.

15 Rademakers R, Neumann M, Mackenzie IR: Advances in understanding the molecular basis of frontotemporal dementia. Nat Rev Neurol 2012;8:423-434.

16 Josephs KA, Duffy JR, Strand EA, Machulda MM, Vemuri P, Senjem ML, Perkerson RB, Baker MC, Lowe V, Jack CR Jr, Rademakers R, Whitwell JL: Progranulin-associated PiB-negative logopenic primary progressive aphasia. J Neurol 2014;261:604-614.

17 Mesulam M, Johnson N, Krefft TA, Gass JM, Cannon AD, Adamson JL, Bigio EH, Weintraub S, Dickson DW, Hutton ML, Graff-Radford NR: Progranulin mutations in primary progressive aphasia: the PPA1 and PPA3 families. Arch Neurol 2007;64:43-47.

18 Deramecourt V, Lebert F, Debachy B, Mackowiak-Cordoliani MA, Bombois S, Kerdraon O, Buée L, Maurage CA, Pasquier F: Prediction of pathology in primary progressive language and speech disorders. Neurology 2010; 74:42-49.

19 Goldman JS, Farmer JM, Wood EM, Johnson JK, Boxer A, Neuhaus J, Lomen-Hoerth C, Wilhelmsen KC, Lee VM, Grossman M, Miller BL: Comparison of family histories in FTLD subtypes and related tauopathies. Neurology 2005;65:1817-1819. 